\title{
Sciendo
}

DOI: $10.2478 /$ lpts-2019-0008

PHYSICAL AND TECHNICAL ENERGY PROBLEMS

\section{SYNTHESIS OF ELECTRONICALLY COMMUTATED SYNCHRONOUS MOTORS WITH PREDEFINED CHARACTERISTICS}

\author{
L. Lavrinovicha, J. Dirba, K. Sejejs, E. Kamolins \\ Riga Technical University, \\ 12/1 Azenes Str., Riga, LV-1048, LATVIA \\ e-mail: ludmila.lavrinovica@rtu.lv
}

\begin{abstract}
The authors present a methodology for the calculation and optimisation of regulation laws that apply to electronically commutated synchronous motors with predefined characteristics. It is shown that the synchronous electronically commutated motors can provide predefined characteristics with the maintenance of high energy performance by simultaneously regulating supply voltage, excitation current and load angle.
\end{abstract}

Keywords: electronically commutated motor, mechanical characteristic, synchronous motor

\section{INTRODUCTION}

Development of semiconductors, microprocessors and motor production technologies makes it possible to solve issues of electric motors with predefined characteristics. The topicality of this task is based on a great variety of electrically driven equipment and the necessity to save energy. The best way to achieve this task is to use electronically commutated motors, which are based on synchronous motors operating in special modes together with a semiconducting commutator and feedback of the motor rotation speed. These types of electrical machines are known as having sufficient power density and efficiency to meet the criteria and requirements of modern electrical drives [1]-[3].

The analysis shows that depending on the commutator circuit and the type of motor excitation electronically commutated synchronous motors can provide a wide spectrum of motor characteristics that are similar to brushed DC motors with shunt, series or compound excitation [3], [4]. The paper [3] shows that in order to ensure the high efficiency of electronically commutated synchronous motors operating with variable load, it is necessary to regulate supply voltage $U_{1}$, excitation current $I_{2}$ and load angle $\theta$.

Results of the studies, which have been carried out until nowadays, and 
the modern microprocessor technologies allow us to formulate the task of motor synthesis and optimisation by combining these two stages in one.

\section{METHODOLOGY FOR THE SYNTHESIS OF THE ELECTRONICALLY COMMUTATED SYNCHRONOUS MOTOR}

The motor synthesis and optimisation task can be conditionally divided into several stages:

- development of the computer program for calculations and optimisation of motor characteristics;

- regulation rule calculations for supply voltage $U_{1}$, excitation current $I_{2}$ and load angle $\theta$, which provide motor predefined characteristics in certain ranges of the variable load;

- electric motor optimisation in order to increase its efficiency during operation in special operation modes;

- determination of the spectrum for characteristics that can be useful to implement in the dimensions of one motor;

- practical implementation of supply voltage $U_{1}$, excitation current $I_{2}$ and load angle $\theta$ regulation.

Armature current $I_{1}$, electromagnetic torque $M$, electric power $P_{1}$, phase shift $\varphi$ (angle between armature current and supply voltage) and magnetization current $I \mu$ of salient pole synchronous motors can be determined from relevant equations [5]:

$$
\begin{aligned}
& I_{1}=\frac{\sqrt{\left[U_{1}\left(\sigma \omega L_{a d} \sin \theta+r_{1} \cos \theta\right)-I_{2} \omega L_{a d} r_{1}\right]^{2}+\rightarrow}}{r_{1}^{2}+\sigma \omega^{2} L_{a d}{ }^{2} A} \rightarrow \\
& \rightarrow \overline{\rightarrow+\left\{U_{1}\left[\omega L_{a d} A \cdot \cos \theta-r_{1} \sin \theta\right]-I_{2} \omega^{2} L_{a d}{ }^{2} A\right\}^{2}} \text {; } \\
& \begin{array}{l}
M=\frac{m \mathrm{p} L_{a d}\left[U_{1}\left(\sigma \omega L_{a d} \sin \theta+r_{1} \cos \theta\right)-I_{2} \omega L_{a d} r_{1}\right]}{r_{1}^{2}+\sigma \omega^{2} L_{a d}^{2} A} \times \\
\times\left(I_{2}+\frac{\left[U_{1}\left(\omega L_{a d} A \cos \theta-r_{1} \sin \theta\right)-I_{2} \omega^{2} L_{a d}^{2} A\right] \times B}{r_{1}^{2}+\sigma \omega^{2} L_{a d}^{2} A}\right) ;
\end{array} \\
& P_{1}=m U_{1}\left[\frac{U_{1} r_{1}+\frac{1}{2} U_{1} \omega L_{a d} A \sin 2 \theta}{r_{1}^{2}+\sigma \omega^{2} L_{a d}{ }^{2} A}+\frac{I_{2} \omega L_{a d}\left[\omega L_{a d} A \sin \theta-r_{1} \cos \theta\right]}{r_{1}{ }^{2}+\sigma \omega^{2} L_{a d}{ }^{2} A}\right]
\end{aligned}
$$




$$
\begin{aligned}
& \operatorname{tg} \varphi=\frac{\omega L_{a d} \cdot\left\{U_{1} \cdot\left[\sigma \sin ^{2} \theta+A \cdot \cos ^{2} \theta\right]-I_{2} \cdot\left[r_{1} \sin \theta+\omega L_{a d} \cdot A \cos \theta\right]\right\}}{U_{1} r_{1}+0.5 U_{1} \omega L_{a d} \cdot A \cdot \sin 2 \theta+I_{2} \omega L_{a d} \cdot\left[\omega L_{a d} \cdot A \cdot \sin \theta-r_{1} \cos \theta\right]} \\
& I_{\mu}=\sqrt{I_{1}^{2}+I_{2}^{2}+2 I_{1} I_{2} \sin (\varphi-\theta)}
\end{aligned}
$$

where $A=\left(\frac{k_{q}}{k_{d}}+\right.$ ó -1$)$,

$B=\left(1-\frac{k_{q}}{k_{d}}\right)$;

$\omega \quad$ is the angular frequency of armature current;

$p \quad$ is the number of pole pairs;

$m \quad$ is the number of phases;

$L_{a d} \quad$ is the inductance corresponding to the flux of armature reaction;

$\sigma \quad$ is the leakage factor of the armature winding;

$r_{1} \quad$ is the active resistance of the armature winding;

$k_{d}, k_{q}$ is the field shape factors.

Equations (1)-(5) correspond to the general case - the salient pole synchronous machine with an excitation winding. In case if $k_{q} / k_{d}=1$ or $I_{2}=0$ it is possible to obtain equations for non-salient pole synchronous machine or synchronous reluctance machine, respectively. In these cases, equations are more simplified. Given the fact that most applied motors in modern electric drives are motors with permanent magnets, which have no excitation winding, permanent magnets have to be conditionally replaced by equivalent winding current $I_{2}$.

Motor mechanical power $P_{2}$ can be calculated by losses of armature current deduction from electric power $P_{1}$. The losses of armature current are proportional to $I_{1}^{2}$, excitation winding losses (proportional to $I_{2}^{2}$, mechanical losses (proportional to $\left.\omega^{3}\right)$ and the losses in the motor core proportional to $\omega^{1.3}$ ). The efficiency factor of the machine is determined as $\eta=P_{2} / P_{1}$. Starting torque $M_{p}$ is determined by equation (2) when $\omega=0$ :

$$
M_{p}=\frac{m p L_{a d} U_{1}}{r_{1}} \cdot\left[I_{2} \cos \theta-\frac{U_{1}}{2 r_{1}} \cdot B \sin (2 \theta)\right] .
$$

In deriving of equations (1)-(5), it is assumed that the phase currents and voltages are sinusoidal, the excitation current has been transmitted to the armature winding, but the magnetic circuit of the motor is unsaturated. 
The computer program for calculations and optimisation of motor characteristics is convenient to be implemented in MS EXCEL with the possibility to print out all necessary graphs and tables.

In case of a synchronous motor without regulation, when $U_{1}=$ const, $I_{2}=$ const and $\theta=$ const, calculations of the motor characteristics are relatively simple. Motor parameters $I_{1}, M, P_{1}, I \mu, \cos \varphi, P_{2}$ and $\eta$, which are used for the definition of the motor characteristics, are calculated from basic equations (1)-(5) of synchronous machines, taking angular frequency $\omega$ as a variable value.

If regulation of the motor parameters is provided, the synthesis and optimisation of the regulation laws for a motor with predefined characteristics are useful to be executed simultaneously.

For the optimisation of synchronous motor characteristics, the following methodology can be suggested.

First, the desirable characteristics, for example, mechanical characteristic $\omega=$ $f(M)$ is pre-set by the graph or table data. Then the permitted ranges of variable parameters $I_{2}, \theta$ and $U_{1}$ are determined. Further calculations are done in the following order: for every point of the predefined characteristic $\omega=f(M)$ values of $I_{2}, \theta$ and $U_{1}$ are calculated by the use of equations (1)-(5) that provide, first, the predefined values of $\omega$ and $M$, and second, optimisation criteria - minimum losses in the studied motor (or maximum $\eta$ ). Regulation rules as $I_{2}=f(M), \theta=f(M)$ and $U_{1}=f(\mathrm{M})$ can be obtained by repeating the same calculations for over several points (usually 5-10) of predefined characteristic $\omega=f(M)$. Depending on the practical implementation in a particular case, regulation rules for the studied motor can easily be obtained as functions of anchor current $I_{1}$ or over motor parameters.

There are two methodologies used for motor optimisation.

In the first case, the optimisation is carried out by calculation of all possible combinations of $I_{2}, \theta$ and $U_{1}$. For this purpose, before starting the calculation, it is necessary to determine both the range and the step of variation for each of the variable parameters. In addition, it is necessary to specify the required values of the torque $M$ and the angular frequency $\omega$ at several points (5-10 points) of the predefined characteristic. The allowable error of the solution has to be specified as well.

Since values of all variables $I_{2}, \theta$ and $U_{1}$ should be changing during the searching of a solution, three nested loops are formed in the program. The values of voltage $U_{1}$ are changing in the outer loop, the load angle $\theta$ - in the middle loop, and the excitation current $I_{2}$ - in the inner loop. The corresponding values of torque are determined for each resulting combination of parameters $I_{2}, \theta$ and $U_{1}$. The purpose of this search is to find such values of the variable parameter for which, with a given accuracy, the value of $M_{i}$ is in the vicinity of the desired value $M$. If the solution is located between present and previous values of the searched $M$, more detailed search is performed by dividing the segment in half. However, any solution, which is found in this way, is only one of several possible options. Combinations of variable parameters $I_{2}, \theta, U_{1}$ with over parameters in interest that ensure maximum efficiency $\eta_{\max }$ are saved.

Such search is repeated for each point of the predefined characteristic $\omega=f(M)$. 
Characteristic $\eta=f(M)$ and regulation laws $I_{2}=f(M), \theta=f(M), U_{1}=f(M)$ that are based on founded combinations of variable parameters are plotted at the beginning of the program.

In the second optimisation case, the calculations are repeated for different initial points that are uniformly distributed in the region of permissible values of variable factors [5], [6]. If the optimisation invariably ends with practically the same values of $I_{2}, \theta, U_{1}$, this indicates that the obtained solution is a global, rather than a local maximum.

Analysis of both optimisation methodologies shows that values of $\eta_{\max }$ obtained by two methods do not differ by more than $5 \%$.

It is necessary to point out that during the calculation and optimisation process for providing the predefined characteristic, all variables $I_{2}, \theta$ and $U_{1}$ cannot be considered as independent variables, but only any two of them. Therefore, each time when values of two variables are chosen at random, for example, $I_{2}$ and $\theta$, the value of the voltage $U_{1}$ correspondently is calculated from equations (1)-(5).

\section{CALCULATIONS OF REGULATION LAWS FOR ELECTRONICALLY COMMUTATED SYNCHRONOUS MOTORS}

Below, as an example, the proposed methodology is illustrated by non-salient pole and salient pole three-phase synchronous motors.

Parameters for studied non-salient pole synchronous motor are as follows: $r_{1}=2,5 \Omega, \sigma=1,07, L_{a d}=0,3 \mathrm{H}, p=3$. Figure 1 shows two predefined mechanical characteristics No. 1 and No. 2 for the studied motor.

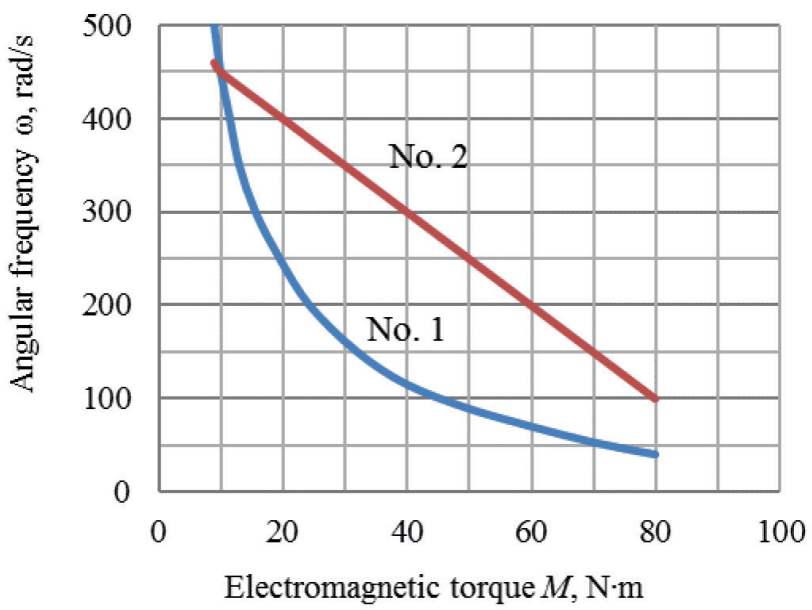

Fig. 1. Predefined mechanical characteristics in the first example.

Regulation laws $I_{2}=f(M), \theta=f(M), U_{1}=f(M)$ and $\eta=f(M)$ for studied non-salient poles that provide predefined mechanical characteristics (Fig. 1) are shown in Fig. 2. In this case, the minimum losses in the studied motor (or maximum efficiency) are accepted as optimisation criteria. The restriction for supply voltage $U_{1}$ is accepted, which does not allow increasing it above the nominal value. 
a)

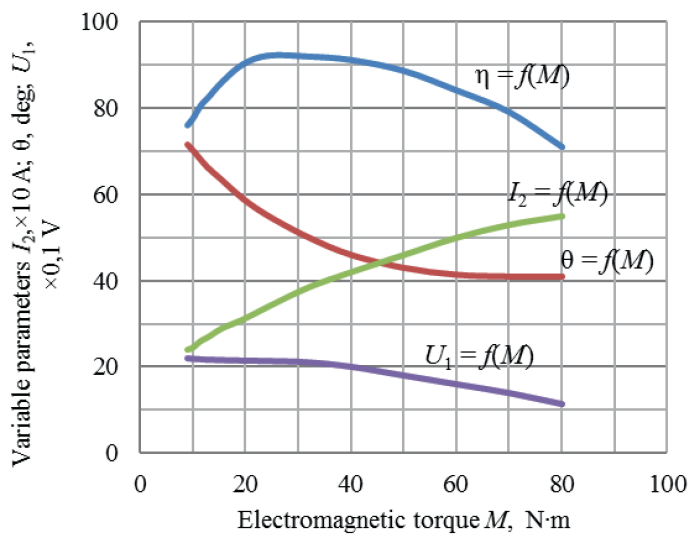

b)

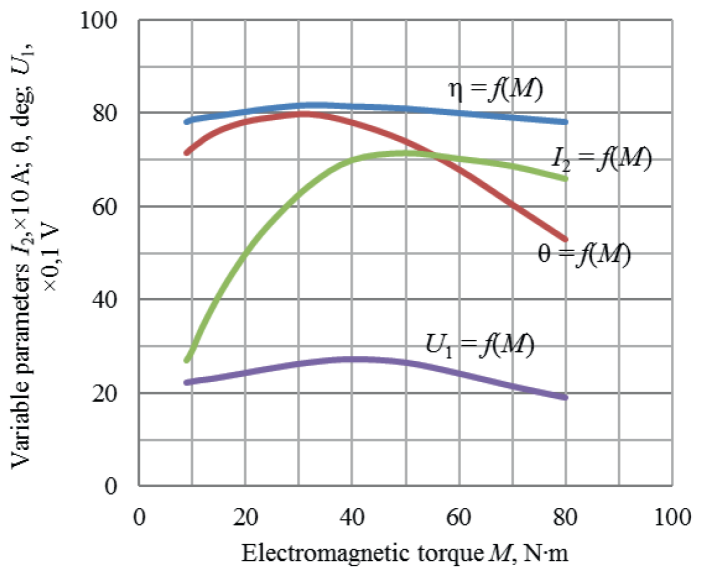

Fig. 2. Regulation laws $I_{2}=f(M), \theta=f(M), U_{1}=f(M)$ and $\eta=f(M)$ for defining non-salient motor characteristics No. 1. (a) and No. 2. (b).

Figures 1 and 2 show that simultaneous regulation of the motor parameters $I_{2}$, $\theta$ and $U_{1}$ can provide the motor predefined characteristics with high efficiency.

Parameters of the studied salient pole synchronous motor: $r_{1}=2.5 \Omega, \sigma=1.07$, $L_{a d}=0.3 \mathrm{H}, p=3$ and $k_{q} / k_{d}=0.8$. Predefined mechanical characteristics No. 1 and No. 2 for the second example are presented in Fig. 3.

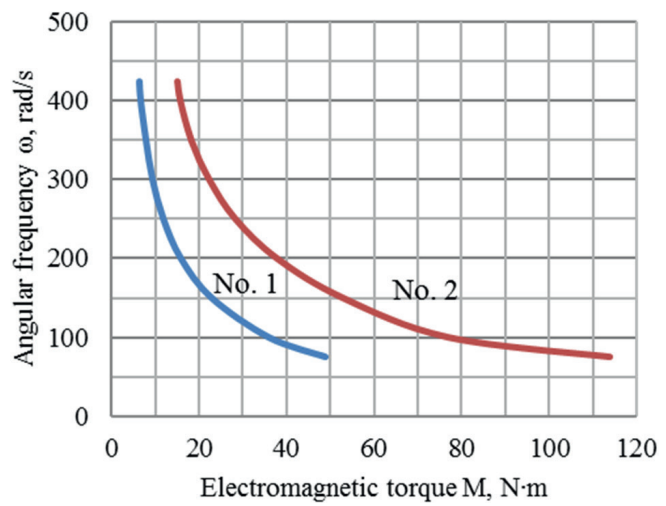

Fig. 3. Predefined mechanical characteristics for the second example. 
Regulation laws $I_{2}=f(M), \theta=f(M), U_{1}=f(M)$ and $\eta=f(M)$ for studied salient poles motor that provide predefined mechanical characteristics (Fig. 3) are shown in Fig. 4.

a)

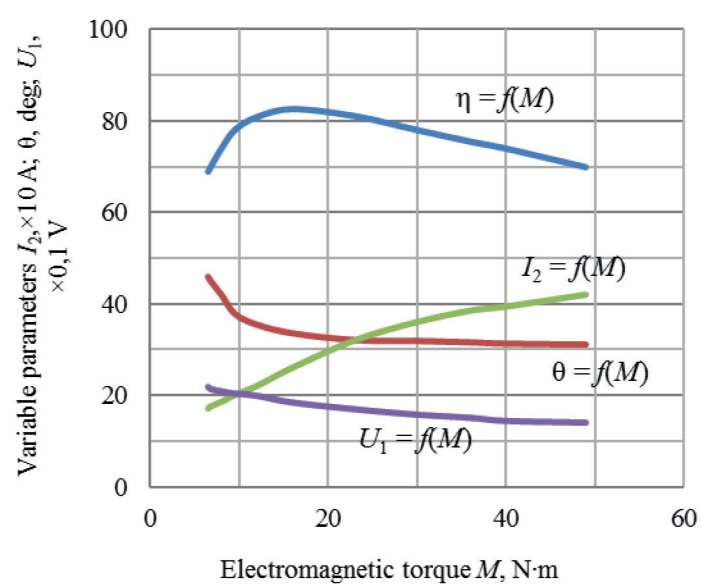

b)

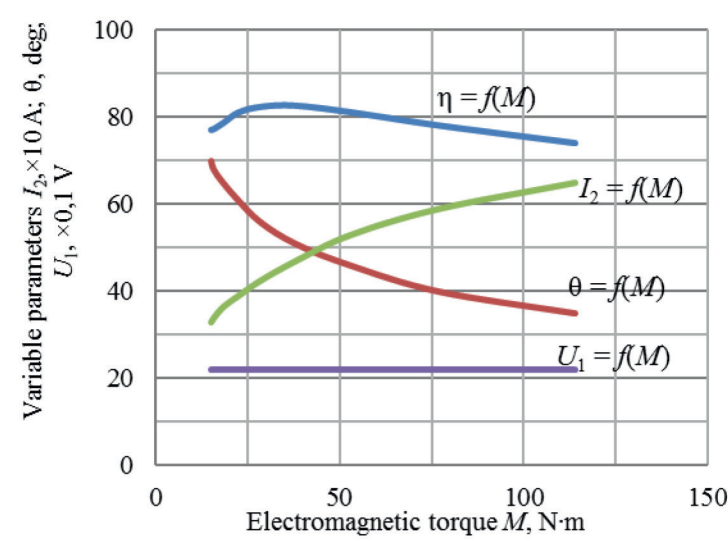

Fig. 4. Regulation laws $U_{1}, I_{2}, \theta=f(M)$ and $\eta=f(M)$ for defining salient pole motor characteristics No. 1. (a) and No. 2. (b).

Comparison of calculated characteristics with the results obtained in the experiments shows that the proposed methodology makes it possible to obtain results, which reflect the nature of the physical process in the motor with a sufficient degree of accuracy.

The analysis shows that by reducing the number of parameters under regulation up to two or just one, the predefined mechanical characteristics can be provided in a narrower range versus to the case where all three parameters are under regulation.

\section{THE PROPOSED SYNCHRONOUS MOTOR CONTROL SYSTEM}

Functional scheme of the synchronous motor control system for validation of the proposed methodology is shown in Fig. 5.

To increase the reliability and efficiency of the variable speed drive of the synchronous motor, a sensorless control circuit has been implemented. The drive 
control method is speed-independent and it is based on commutation thresholds by sensing the terminal voltage differences between two control states of each phase of the armature winding. From these differences, the actual rotor position $\theta$ can be calculated using rotor speed and position calculation algorithm [7], [8].

For the terminal voltage and current measurement, a block with voltage and current sensors for each phase of the armature winding is used. This control method is effective from the start-up of the synchronous motor up to $100 \%$ PWM duty cycle of the three-phase inverter. When the PWM duty cycle approaches $100 \%$, the rotor position is obtained by calculation of the zero-crossing point (ZCP) of backelectromotive force (back-EMF), thus achieving full-speed range sensorless control of the synchronous motor [9].

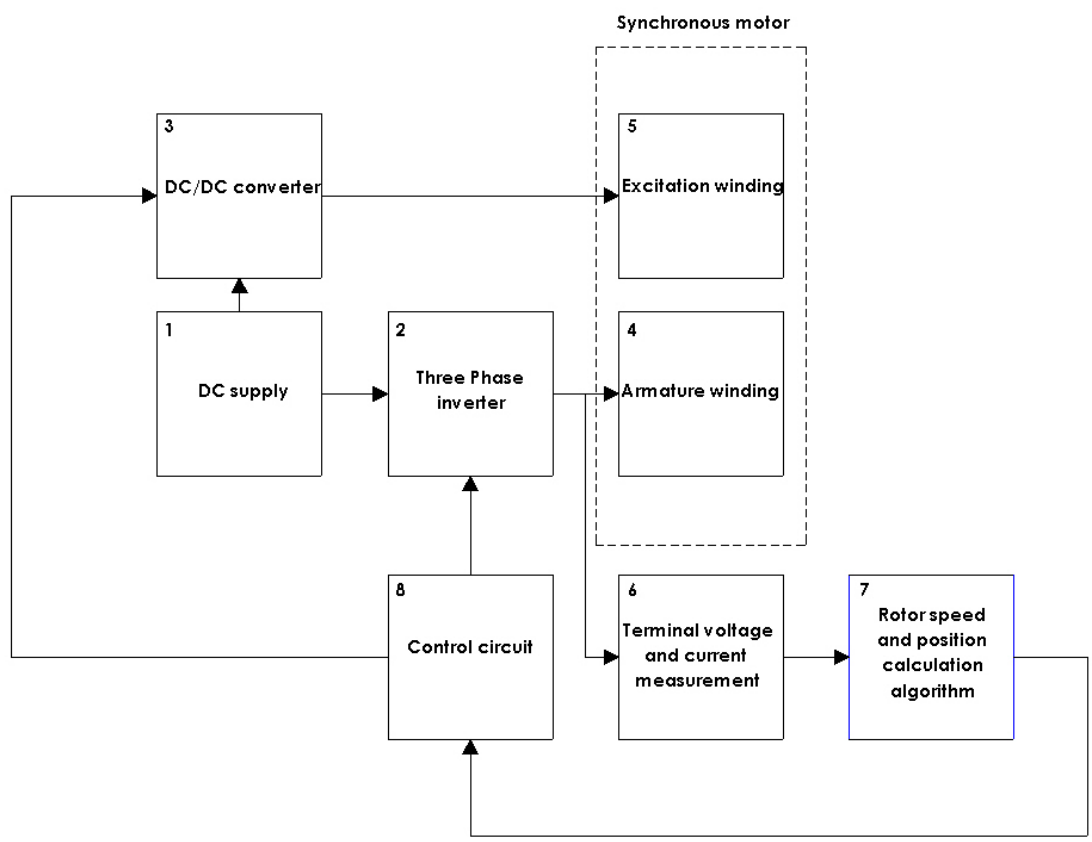

Fig. 5. Functional scheme of the synchronous motor control system.

\section{5, CONCLUSIONS}

Based on the results obtained within the framework of the conducted research, the following conclusions can be drawn:

1. The proposed methodology makes it possible to synthesize motors with predefined and variable characteristics.

2. Reducing the number of parameters under regulation narrows the ranges of the set characteristics.

3. In the proposed synchronous motor control system position closed-loop control is used at the beginning of the motor operation.

4. Commutation instants are acquired directly instead of a phase shift from the zero-crossing point (without low-pass filters) in the commutation threshold-based method. Therefore, there are no phase delay problems. 
5. Precise parameters of the synchronous motor are not needed.

6. The proposed control system is easy to implement because it requires no extra hardware components (low cost) and there are no complicated computations.

\title{
REFERENCES
}

1. Irimia, N. D., \& Lazar, F.I. (2017). A comparative study of different BLDC motor construction types used in automotive industry under specific command strategies. In 22nd IMEKO TC4 International Symposium \& 20th International Workshop on ADC Modelling and Testing, 14-15 September, 2017, Romania.

2. Olusegun, S. (2007). Model reference adaptive control of a permanent magnet brushless DC motor for UAV electric propulsion system. In 33rd Annual Conference of the IEEE Industrial Electronics Society, 5-8 November 2007, Taipei, Taiwan.

3. Dirba, J., Lavrinovicha, L., Levins, N., \& Pugachevs, V. (2012). Application of synchronous brushless motors in electric hand tools. Latvian Journal of Physics and Technical Sciences, 49(1), 29-34. ISSN 0868-8257.

4. Lavrinovicha, L., \& Dirba, J. (2015). Brushless synchronous motors with external rotor. Riga: RTU Publishing House. (in Latvian)

5. Auzins, J., \& Janusevskis, A. (2011). Planning and analysis of experiments. Riga: RTU Publishing House. (in Latvian)

6. Eglajs, V. (1980). Algorithm for intuitive search to optimize complex systems. Problems of dynamics and strengths. Riga: Zinatne Publishing House, pp. 28-33. (in Russian)

7. Lin, N., Qiu, J., \& Shi, C. (2018). A Full-speed range sensorless control scheme of brushless DC motor based on saliency effects. In 21st International Conference on Electrical Machines and Systems (ICEMS) (pp. 1654-1658), 7-10 October 2018, Korea.

8. Miller, T.J.E. (2001). Electronic control of switched reluctance machines. Newnes Power Engineering Series.

9. Ahmad, F., Zaid, M., \& Pandey, M. (2018). Sensorless control of brushless DC motor by zero-crossing detection pulse generation with adaptive power factor control technique. In IEEE International Conference on Environment and Electrical Engineering and IEE Industrial and Commercial Power Systems Europe (EEEIC / I\&CPS Europe), 12-15 June 2018, Palermo, Italy.

\section{SINHRONO VENTIL̨DZINĒJU SINTĒZE AR IEPRIEKŠ UZDOTĀM RAKSTURLİKNEM}

\author{
L. Lavrinoviča, J. Dirba, K. Sējējs, E. Kamoliņ̧̌
}

Kopsavi $1 \mathrm{kums}$

Piedāvāta regulē̌sanas likumu aprēķinu un optimizācijas metodika ventiḷdzinējiem ar iepriekš uzdotām raksturlīknēm. Parādīts, ka vienlaikus regulējot barošanas spriegumu, ierosmes strāvu un slodzes leņki, sinhronais ventil̨zzinējs var nodrošināt iepriekš uzdotās raksturlīknes, saglabājot augstus enerǵētiskos rādītājus.

05.03.2019. 